\title{
Uma Viagem Ao Vale Do Rio Doce: A Biodiversidade Renasce Nas
}

\section{Fotos De Sebastião Salgado}

\section{A Journey To The Sweet River Valley: Biodiversity Reborn In Sebastião Photos Salgado}

Domingos Sávio Gonçalves¹, Prof. Dr. Mauro Maia Laruccia²

\begin{abstract}
1. Mestrando em Comunicação e Cultura -UNISO. Graduado em Gestão Ambiental pela UFSP-IFSR.
2. Pós Dr. Professor do Programa de Pós-Graduação em Comunicação e Cultura da Universidade de Sorocaba (UNISO. E-mail: maurolaruccia@prof.uniso.br. Pos doc e Doutor em Comunicação e Semiótica pela Pontifícia Universidade Católica de São Paulo. Mestre e Bacharel em Administração de Empresas pela PUC/SP. Professor: do Programa de Mestrado na UNISO, de Tecnologias da Informação e Educação da Universidade Braz Cubas, com pesquisa apoiada pela FAPESP, da FEA/PUCSP, da graducão e Pós- das Faculdades Integradas Campos Salles. Avaliador Ad Hoc do INEP/MEC. E-mail:mauro.laruccia@gmail.com .
\end{abstract}

\section{Resumo}

Duas impactantes e midiáticas imagens do renomado repórter fotográfico Sebastião Salgado documentaram o renascimento da biodiversidade em terras degradadas da Fazenda Bulcão na cidade de Aimorés-MG, no vale do Rio Doce. Este trabalho tem como objetivo descrever, a partir dessas duas fotografias e de uma visita à RPPN ${ }^{1}$, o visível sonho realizado de Sebastião Salgado e sua esposa de plantar ali um importante fragmento de mata atlântica e ver o ressurgimento das nascentes de águas e da vida em pouco mais de uma década. O Instituto Terra é um exemplo de proteção particular da natureza e também de como a comunicação é importante para sensibilizar, ampliar consciências, formar cidadania e divulgar as ações de proteção da natureza no Vale do Rio Doce.

Palavras-chave: Comunicação; Meio Ambiente; Instituto Terra; Narrativa fotográfica;

\footnotetext{
${ }^{1}$ RPPN- Reserva Particular do Patrimônio Natural
} 


\begin{abstract}
Two striking and media images of the renowned photojournalist Sebastião Salgado, documented the renaissance of the biodiversity in the degraded lands of Bulcão Farm, in the city of Aimorés-MG, in Rio Doce's valley. This paper aims to describe, from these two photographs and a visit to RPPN, the visible accomplished dream of Sebastião Salgado and his wife, of planting an important fragment of the rainforest and see the resurgence of water springs and of life in a little more than a decade. The Earth Institute is an example of nature's private protection and also of how communication is important to raise awareness, expand consciousness, to form citizenship and disclose the actions of nature's protection Rio Doce's valley.
\end{abstract}

Keywords: Communication; Environment; Earth Institute; Photographic narrative;

\section{Introdução}

Sebastião Salgado, doutor em economia e repórter fotográfico brasileiro de projeção internacional, tem se valido exitosamente de suas fotografias e da mídia nacional/estrangeira como aliada espontânea na divulgação das ações do Instituto Terra e também como um meio eficaz para levar sua mensagem de conscientização ambiental aos povos do Brasil e do mundo.

Com sua grande visibilidade midiática mundial, ele não fica apenas no campo das denuncias com suas marcantes imagens do mundo, palestras, entrevistas aos mais importantes jornais e revistas, nem no discurso da necessidade de replantar árvores para proteger rios/nascentes, minimizar a grave falta de água e fazer renascer a biodiversidade onde ainda é possível e urgente.

Em seu trabalho e em suas ações comprovadas, pensa o meio ambiente como "espaço onde interagem, em conjunto, os elementos naturais, artificiais e culturais. É onde a vida acontece, onde se convive, o habitat, o lugar, o sitio, o recinto". (MILARÉ, 2001, p.63)

É o "mundo à volta, à volta do mundo". (SILVA, 2000, p. 20). Salgado é holístico quando considera o meio ambiente "um bem comum do povo e o resultado das relações do homem com o mundo natural no decorrer do tempo"'. (MILARÉ, 2001, p. 64).

O mundo que ele defende é sustentável, isto é, onde caminhos, planos, soluções resgatem práticas saudáveis de vida, as necessidades presentes sejam supridas sem 
interferir nas gerações futuras e os recursos naturais necessários mantidos para as futuras gerações.

É em Minas, na sua cidade de Aimorés que se localiza a Fazenda Bulcão, transformada em 1998 em Reserva Particular do Patrimônio Natural, num gesto espontâneo, muito simples, mas de valor imenso para a recuperação e conservação dos recursos naturais do Brasil e consequentemente do Planeta Terra.

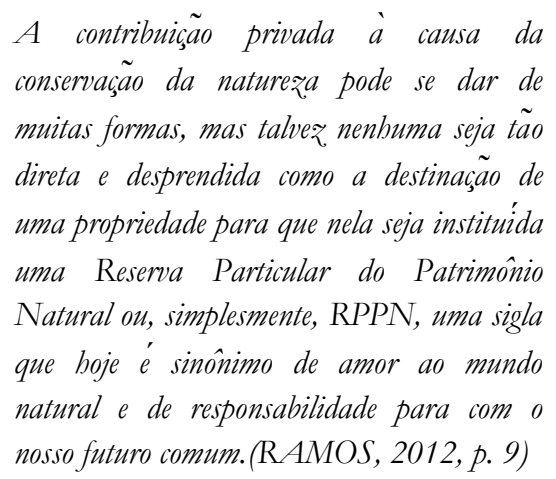

Uma vez criada a RPPN, a lei diz que ela tem que ser gravada com perpetuidade, ou seja, não pode ser descriada nem mesmo pelos herdeiros em qualquer tempo. Mas se o objetivo do proprietário é mesmo o de proteger a natureza para hoje e para o futuro, isso não é certamente um problema.

A comunicação das ações do Instituto Terra nos mais importantes veículos nacionais e internacionais tem grande importância para a população do Vale do Rio Doce e do Brasil, já que permite desenvolver nela a percepção do problema e um maior comprometimento com as ações de preservação do meio onde vivem.
Teresa Urban, jornalista e ambientalista dedicada aos problemas ambientais desde os anos 90, em seu artigo "O meio ambiente na mídia - um estudo de caso do jornal de maior circulação de Brasilia" reforça a necessidade do cidadão ser informado pela mídia, já que a não informação cria pelo menos três grandes problemas para o meio ambiente:

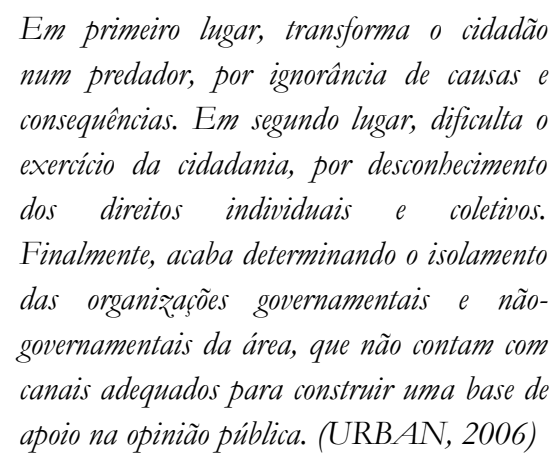
num predador, por ignorância de causas e consequências. Em segundo lugar, dificulta o exercício da cidadania, por desconbecimento dos direitos individuais e coletivos. Finalmente, acaba determinando o isolamento das organizações governamentais e nãogovernamentais da área, que não contam com canais adequados para construir uma base de apoio na opinião pública. (URBAN, 2006)

\section{No vale do rio doce}

Para chegar a Aimorés, partindo de Caratinga, a viagem é de pouco mais de $150 \mathrm{~km}$ e muitas curvas no caminho. É a região do Vale do Rio Watu para os índios Aimorés ou Doce como é conhecido o importante rio da história de Minas Gerais, que hoje carrega em suas águas a preocupante posição de $10^{\circ}$ mais poluído do país.

Um Rio "morto, mas morto de uma maneira que é morto mesmo - uma calha estéril de lama" (SALGADO, 2015), após os impactos ambientais provocados pelo desmoronamento das barragens da mineradora Samarco/Vale no município de Mariana. 
Sou um rio de muitas memórias. Mas, sou também um sobrevivente. Visto pela primeira vez no ano de 1501, por navegadores portugueses quando percorriam a costa brasileira, permaneci no anonimato por muitos e muitos anos, ausente até mesmo nas cartas dos jesuitas que viveram tão perto de mim. Muitos são os mistérios que encobrem a conquista de meu território, marcado por desafios que tornaram amarga a vida de aventureiros frustrados, porém, doce, para aqueles que nele encontraram riquezas em abundância. Sou conbecido por rio Doce, mas antes mesmo de receber este nome, os indios 'Aimorés' me chamavam de 'watu'. (ALMEID A, 2014)

Carlos Drummond de Andrade, brasileiro, poeta mineiro de Itabira também no Vale do Rio Doce, anteviu, num poema profético de 1984 as tensões entre o "Nilo Brasileiro" e as mineradoras que o exploram desde sempre e hoje uma das principais causas do aceleramento de sua morte:

Lira Itabirana
O Rio? É doce.
A V ale? Amarga.
Ai, antes fosse
Mais leve a carga.
Entre estatais
E multinacionais,
Quantos ais!
A divida interna.
A divida externa
A divida eterna.
Quantas toneladas exportamos
De ferro?
Quantas lágrimas disfarçamos
Sem berro?

Há muitos morros e montanhas na estrada e não é à toa que "ser mineiro é viver nas montanhas" (ANDRADE, 2015). Dizem, os de lá, que em Minas tem tanto morro que depois do morro... tem morro uai.

Nos tortuosos caminhos de Minas e do vale, a paisagem é sempre muito bonita, mesmo quando se passa por intermináveis plantações de eucaliptos exóticos (originários da Austrália), as chamadas florestas comerciais ou do capital financeiro que reduzem a biodiversidade, afetam os lençóis freáticos, alteram a qualidade do solo e destroem a capacidade futura de produção de alimentos. Onde se planta eucaliptos em larga escala os pássaros, alguns mamíferos e as plantas desaparecem.

A exuberante mata atlântica que cobria toda a extensão do vale deu lugar a extensas pastagens para pecuária e hoje as matas se resumem a fragmentos de reservas nos topos de morros. Um riquíssimo patrimônio da biodiversidade foi sacrificado para se obter uma produção cada vez menor de carne e leite.

De repente, num trevo da estrada, o asfalto acaba e a viagem tem que ser feita por um caminho estreito de terra com muita poeira, margeando um lindo rio de águas claras e uma mata atlântica absolutamente preservada.

A primeira sensação é de estranhamento, pois se viaja numa região consolidada onde estradas federais de terra praticamente não mais existem. Menos de 10 $\mathrm{km}$ à frente o asfalto volta e para surpresa uma placa indica que a área de estrada de terra é uma 
Reserva Biológica-

a RPPN de Feliciano

Miguel Abdalla, que, além de conservar intacta mais de 950 ha contínuos de floresta à esquerda do rio, protege os Muriquis ${ }^{2}$, o maior primata das Américas.
Está explicado e mais que justificado a ausência de asfalto, necessária para diminuir a velocidade dos veículos e barulho, (muriquis não gostam de barulho) reduzir os atropelamentos de animais e permitir que eles possam, ainda que com certo risco, beber água no rio Manhuaçu.

\footnotetext{
2 Encontrado somente na Mata Atlântica, o muriqui é o maior primata das Américas. Eles não são agressivos e demonstrações de afeto são comuns entre indivíduos de qualquer sexo ou idade. Uma das características marcantes desses macacos são os demorados abraços grupais. Os adultos sempre cuidam dos mais jovens e fazem pontes com o próprio corpo para facilitar a passagem de filhotes de uma árvore para outra. Por conta de toda essa passividade, os muriquis são chamados pelos índios de "povo manso da floresta". (PASCHOAL, 2014)
}

\section{Aimorés - MG}

Aimorés é banhada pelo Rio Doce. Fica no leste do estado, na divisa com o Espírito Santo. Tem esse nome em homenagem aos índios Aimorés, primeiros habitantes da região. Eles eram canibais e por muito tempo ajudaram na preservação das matas do atual município (LEITÃO, 2014).

O desbravamento do Vale onde fica o município ocorreu a partir de 1856 quando os primeiros posseiros chegaram e ocuparam as terras das cabeceiras do Rio Pocrane, margeando-o até o Rio Manhuaçu e dai até a confluência com o Rio Doce.

Como a região oferecia vantagens econômicas com seus rios piscosos, solo fértil e caça abundante, a agricultura e pecuária foram incentivadas e logo chegaram novos posseiros que povoaram o local até então dominado pela tribo dos Aimorés.

A construção da ferrovia Vale do Rio Doce acelerou os distúrbios ambientais, devido à elevada demanda por lenha e aos incêndios provenientes de fagulhas lançadas pelas locomotivas. (TERRA, 2015). A exploração da madeira por multinacionais estrangeiras e grandes madeireiras nacionais, em grande escala, redundou no desmatamento generalizado de mata atlântica e no empobrecimento de terras.

Outras atividades agrícolas como a cafeicultura e a pecuária intensiva foram realizadas sem a mínima preocupação com a 
conservação dos recursos naturais, contribuindo para o estado atual de degradação da região.

A ausência de oportunidade econômica definiu um quadro de êxodo rural da população local e a estagnação das áreas urbanas do município. No período de 1970 a 2006 a cidade perdeu cerca de $40 \%$ de sua população que migrou para outras cidades e para o exterior. Atualmente 25.000 pessoas habitam o município (VALE, 2006).

Sebastião Salgado pai trabalhava a terra com a mesma lógica dos fazendeiros mais antigos que tinham, por consenso, o costume de "desmatar para fazer pastagens e criar o maior número possível de cabeças de gado" (LEITÃO, 2014). A exploração dos recursos naturais ocorreu de forma indiscriminada e hoje a maioria das fazendas se prestam a uma agricultura de subsistência e pecuária de baixa produtividade.

As palavras de Sebastião Salgado em uma entrevista ao jornal argentino El Clarin narram a situação encontrada na Fazenda Bulcão, e que é visível na foto de 2001:

La tierra estaba tan enferma como yo, 'estaba todo destruido', afirmó Salgado. 'Solamente alrededor de un 0,5\% de la tierra estaba cubierta por árboles'.

'Quizás tenemos una solución. Hay un solo ser que puede transformar el $\mathrm{CO}_{2}$ en oxígeno, un árbol. Necesitamos reforestar el bosque. Se necesitan bosques de árboles nativos, y se necesita recoger las semillas en la misma región que se plantan, o las serpientes y las termitas no vendrán. $Y$ si se plantan árboles en bosques a los que no pertenecen, los animales no vendrán y el bosque estará en silencio'. 'Necesitamos escuchar la palabra de las personas de la tierra. La naturaleza es la Tierra y otros seres, y si no tenemos una especie de retorno espiritual a nuestro planeta, creo que estaremos comprometidos. (CLARIN, 2015)

Em uma de muitas entrevistas à revista francesa Paris Match, lida por formadores de opinião no mundo inteiro e sobretudo na Europa, Sebastião Salgado e sua esposa Lélia contam como tiveram a ideia de recriar a floresta e a consequente biodiversidade nas terras de sua infância.

É possível sentir o entusiasmo, ressaltado pela Paris Match, quando ele diz que tudo voltou na Fazenda Bulcão: as borboletas, os pássaros, as águas que brotam das nascentes e a vida na exuberancia da mata Atlântica renascida.

\section{Fotografias De Sebastião Salgado}

Deu-se uma importância exagerada ao texto escrito na formação das gerações recentes (FRANCASTEL, 1993). Ocorre que o homem não vive só das palavras, mas também dos olhos e dos ouvidos.

\footnotetext{
${ }^{3}$ A terra estava tão doente como eu. 'Tudo estava destruído, disse Salgado'. 'Apenas cerca de $0,5 \%$ da terra estava coberta por árvores. 'Talvez tenhamos uma solução. Existe um ser que pode transformar $\mathrm{CO}_{2}$ em oxigênio, uma árvore. Nós precisamos reflorestar a terra. Árvores florestais nativas são necessárias e precisamos coletar as sementes na mesma região ou cobras e cupins não virão. $\mathrm{E}$ se as árvores são plantadas nas florestas que não pertencem, outros animais não virão'. 'Precisamos ouvir a palavra do povo da terra. A natureza é a Terra e os outros seres, e se não temos um retorno espiritual ao nosso planeta, eu acho que estaremos comprometidos'. Tradução nossa.
} 
A fotografia integra hoje várias áreas do conhecimento, em todas as suas formas e níveis. Ela fornece inúmeras possibilidades plásticas e gráficas, ao mesmo tempo em que gera questionamentos e produz sentimentos, preocupações e dúvidas ao homem comum quando a contempla.

Quando a imagem fotográfica mostra um acontecimento ela "pode provocar novas percepções, produzir subjetividade inerente ao ato de olhar e imortalizar o fato e o espaço captado, contextualizando-o" (GOMES, 1996, p.8).

Para (MONTEIRO, 1998, p.364) a fotografia é uma importante manifestação da poética visual contemporânea. Ao invés de suporte, ela se transforma numa fonte de estudos de sociologia da comunicação, através de pesquisas experimentais.

Ainda segundo (GOMES, 1996, p.8), com a fotografia tem-se uma oportunidade de trabalhar a percepção ambiental por meio da sensibilização; ou, ainda, utilizar uma imagem de anos passados e outra recente, de um local, para demonstrar a devastação, por exemplo.

Fotografar, é uma forma de expressão, o congelamento de uma situação e seu espaço físico inserido na subjetividade de um realismo virtual (MONTEIRO, 1998, p.364).

A imagem fotográfica pode ser um “instrumento eficaz e detonador da capacidade perceptiva ou indicador do estágio de percepção” (FERRARA, 1999). Uma imagem, se não for capaz de sensibilizar, pode, pelo menos, demonstrar o conhecimento que tem o observador do assunto meio ambiente.

A narrativa fotográfica está mais perto da realidade, pois a paisagem ou objeto retratado está mais próximo do que vemos fisicamente. Há, nela, uma linguagem cheia de significados que podem ter interpretações diversas, de acordo com as experiências vividas pelo fotógrafo e por quem observa o resultado da fotografia.

Numa fotografia, cujo foco é o meio ambiente em sentido mais amplo, os sinais de vida e a biodiversidade são congelados. Suas várias facetas podem tanto ser uma testemunha do que passou quanto a própria base para um novo olhar. É o olhar ambiental, que surge na fotografia para facilitar e permitir a aquisição de novos conhecimentos, valores, comportamentos, atitudes e perceber o meio ambiente onde vários aspectos interagem.

Sebastião Salgado, em suas fotografias, leva as pessoas à uma reflexão sobre o meio ambiente, a situação econômica e social, a cultura e a vida do local retratado. Do seu olhar surgem imagens que chocam por mostrar a realidade "nua e crua da pobreza, da dor e da fome" (MURITIBIS, 2015).

Para Janio de Freitas, premiado e conceituado jornalista brasileiro atualmente na Folha de São Paulo, as fotografias de Salgado revelam mais que uma exposição racional dos 
problemas econômicos e sociais. E complementa:

O que quer dizer que sua fotografia não se descreve: sente-se. E sente-se de um modo especial, proveniente do que fez Sebastião Salgado ser reconbecido em todo o mundo, em tão poucos anos, como um fotógrafo muito especial.

Diante de sua fotografia não se pode sentir, como é usual que as fotografias provoquem, a ternura, on a contristação, on a culpa, on o deleite estético. Diante da fotografia característica de Sebastião Salgado vêm-nos, em uma rajada única, a ternura e a dor e a culpa e o prazer estético. Inseparáveis e indistinguiveis, consistentes e indisfarçáveis, em uma só rajada, todos os ricos sentimentos que a pobreza emocional dos dias de hoje não foi ainda capaz de consumir e devorar. (FREITAS, 1992)

As duas fotografias aqui expostas, como todas de Salgado, foram realizadas em preto e branco. Essa ausência de cor enfatiza o drama, a dor, o desespero e significa ausência de informação (MURITIBS, 2015) pois o objetivo é o de chamar a atenção, de quem observa, para a situação e momentos retratados.

No caso temos duas situações precisas, vistas de um mesmo ângulo, foco e enquadramento: Em 2001 a imagem mostra um cenário de terra arrasada e em 2013 uma nascente mata atlântica que cobre toda a paisagem.

Numa é a vida que se foi e ainda estava indo e na outra é a vida que voltou e ainda está chegando.

Afora o impacto negativo (na de 2001) e o positivo, (na de 2013) para quem as observa, e teve a oportunidade de comprovar in-loco nessa viagem ao Vale, as imagens provocam reflexões de caráter politico, social, econômico e ambiental. Afinal por que se chegou a essa situação em toda a costa brasileira? $O$ que ainda pode ser feito para recuperar e preservar o bioma em outras fazendas? Faz sentido desmatar em pleno século 21 para plantar tanto eucalipto? Criar pastagens para uma atividade agropecuária de baixa produtividade? Qual o futuro da região se os rios continuarem morrendo? O que será das populações? Migrarão para que lugar se o problema é generalizado? O que será das futuras gerações? Que tipo de comunicação será eficiente para incentivar outros proprietários de fragmentos de matas/áreas degradadas a transformarem suas fazendas ou parte delas em áreas de preservação natural do Patrimônio Particular (RPPN)? 


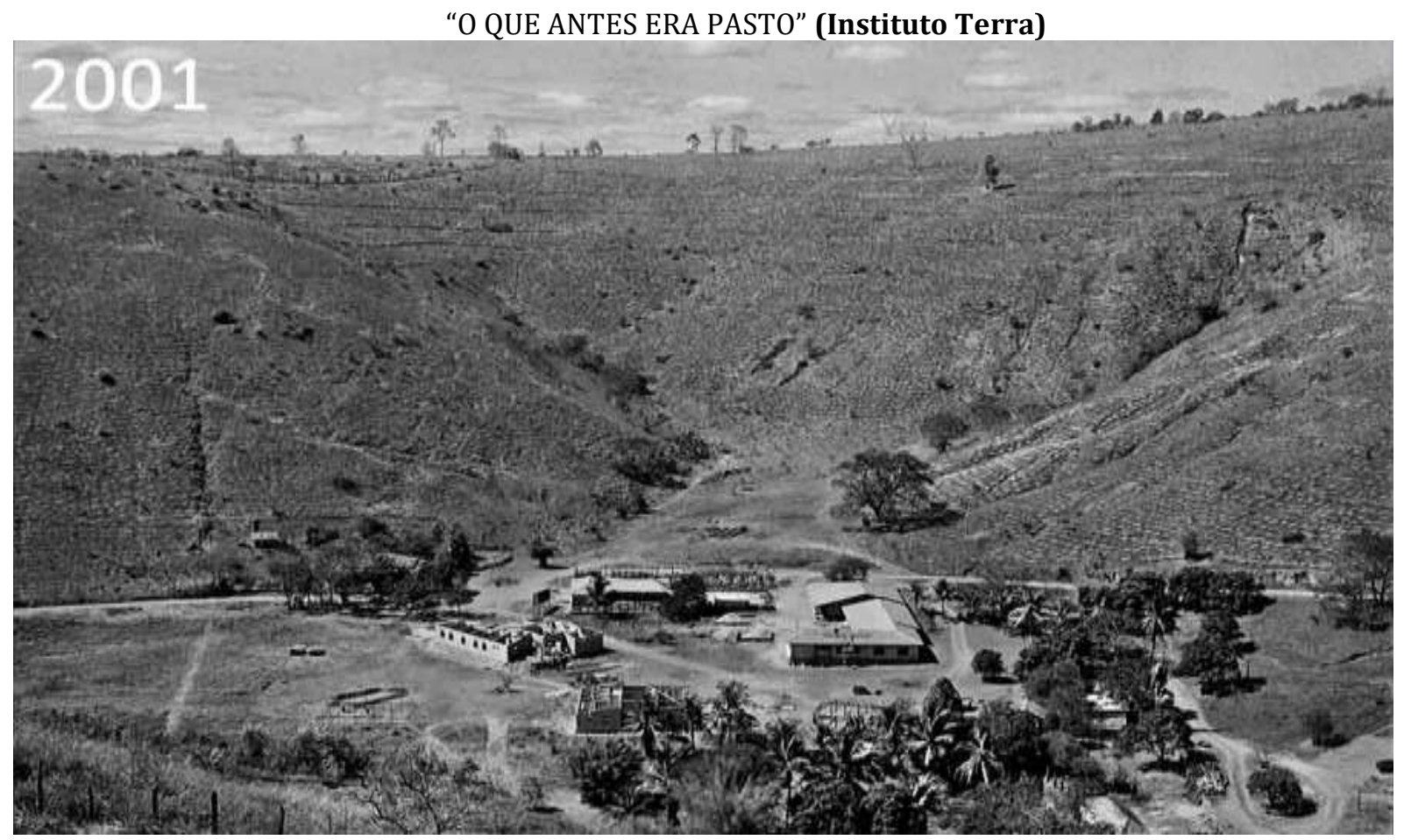

Fazenda Bulcão em 2001

Fonte: Sebastião Salgado

É com essa imagem em seu site institucional que o Instituto Terra se apresenta aos internautas. e aos que visitam a fazenda. A frase em português "O QUE ANTES ERA PASTO" é significativa para quem pode ver nela um primeiro impacto: uma paisagem feia, cinzenta, com pouca vida e ferida de morte pela ação antrópica.

Para (VERAS, 2013) a paisagem é identidade de um povo, porque é produto de uma relação necessária que o homem estabelece com a natureza para se consolidar e construir o seu território.
Quando a paisagem é destruída, como no caso da foto, "perde-se também parte da identidade, da memória e dos valores que se manifestam naquilo que é visível e que o olhar apalpa”. (VERAS, 2013). Já não se vê as especificidades dos lugares e de sua história, as formas de vida que ali havia e já não se sabe como as pessoas interagiam no lugar.

Nasci em uma fazenda, uma fazenda que era mais de 50 por cento floresta tropical. Um local maravilhoso. Vivi com pássaros incriveis, animais incriveis, nadei em pequenos rios com jacarés. Aproximadamente 35 famílias viviam nessa fazenda, e tudo que era produzido nessa fazenda, nós consumiamos. 
Muito pouca coisa ia para o mercado. Uma vez. por ano, a única coisa que ia para o mercado era o gado produzido, e fazíamos viagens de mais ou menos 45 dias para chegar ao abatedouro, trazendo milhares de cabeças de gado, e cerca de 20 dias de viagem para voltar à nossa fazenda novamente. (SALGADO, 2013)

Sebastião estava em plena depressão quando seus país deixaram a fazenda Bulcão como herança para ele e seus irmãos. Quando ele e sua esposa regressam a Aimorés para visitar o lugar o espanto é total pois pouco da paisagem vista lembrava seus tempos de criança. Já não havia os pequenos rios, os pássaros, as borboletas e as famílias. As florestas estavam devastadas. Alguma coisa precisava ser feita.

\section{...AGORA É FLORESTA (Instituto Terra)}

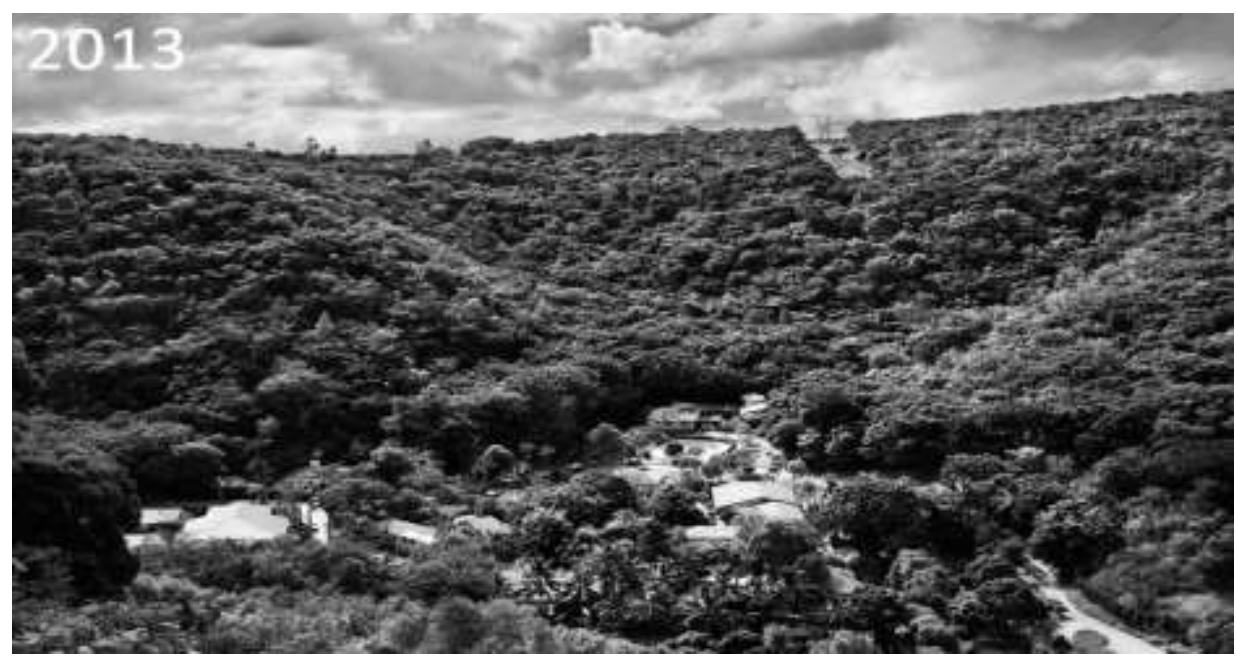

Fazenda Bulcão em 2013

Fonte: Sebastião Salgado

Ao ver aquela terra devastada pela agricultura intensiva caminhando para uma quase desertificação (foto de 2001), Lélia, sua esposa, teve uma ideia magnifica: E se nós recriamos a floresta? Precisamos plantar 2...5 milhões de árvores! (ISÈRE, 2013). Um grande desafio, mas os dois amam os desafios. Nasceu ali o Instituto Terra, uma fundação destinada à Ecologia.

Los pájaros fueron los primeros en regresar cuando la selva tropical brotó de nuevo. Hoy sus cantos alegran los paseos por el bosque. El

\begin{abstract}
vuelo sostenido del beija-flor, colibri en español, es un espectáculo. Simpático, de colores vivos y metálicos, frena su vuelo con un estilo único para besar las flores, como su nombre indica, y asi extraer el polen. Pero la gran reina de la selva emergente de Lélia y Tião, como llaman sus próximos a Salgado, es el ocelote, conocido en Brasil como "onça jaguatirica", un leopardo algo más pequeño que ya ha asomado sus dotes de cazador por la montaña (EL MUNDO, 2015). ${ }^{4}$
\end{abstract}


Todas as pessoas (turistas, estudantes, pesquisadores, ecologistas) que visitam a fazenda e a região já podem ver e comprovar, decorridos poucos mais de uma década, a realização do sonho de replantar um grande e importante fragmento de mata atlântica.

O verde voltou exuberante, as águas renasceram, a biodiversidade resgatada já é uma realidade retratada nos jornais, redes sociais, TVs e revistas de todo o mundo. O Instituto Terra se abriu às pesquisas, estudos, turismo sustentável, ações de caráter cultural e emprega muitas pessoas da cidade e região.

\footnotetext{
Quinze ans plus tard, 2,5 millions d'arbres ont été replantés. Deux cent quatre-vingt-dixsept espèces se réinstallent au fur et à mesure que la forêt mûrit, que la chimie du sol se transforme. Les animaux reviennent - les jaguars, les papillons, les caïmans, plus de cent soixante-dix espèces d'oiseaux, et, derniers arrivés, les singes... La propriété familiale est devenue Instituto Terra, réserve nationale protégée. Autour de l'ancienne étable, barmonieusement plongés dans les bougainvillées fuchsia et les ipés en fleur, de sobres bâtiments en bois d'eucalyptus se sont multipliés, conçus par Lélia, architecte de formation. Ils abritent un laboratoire de semences, collectées dans un rayon de 300 kilomètres, un centre écologique éducatif avec réfectoire, chambres (cent quarante lits), salles de classe, théatre-cinéma et même petit musée (ZARACHOWICZ, 2014).5
}

\footnotetext{
pelos seus mais próximos, é a jaguatirica, um leopardo um pouco menor que mostra suas habilidades como caçador nas montanhas. (Tradução nossa)

${ }^{5}$ Quinze anos mais tarde, 2,5 milhões de árvores foram replantadas. Duzentas e oitenta e sete espécies se reinstalaram na medida em que a floresta ficou madura, a química do solo se transformou. Os animais voltaram, as jaguatiricas, as borboletas, os jacarés, mais de setenta espécies de pássaros e por ultimo os macacos. Em torno do antigo estábulo, harmoniosamente mergulhado no meio dos
}

A RPPN - Fazenda Bulcão - Instituto Terra, semeia hoje sementes e conhecimento na região e é um exemplo para grandes proprietários que, sem deixar de produzir os grãos da terra, podem e devem recuperar/preservar suas florestas, suas águas, seus rios, a cultura e as vidas do lugar.

Ao visitar a região de Aimorés, o Instituto Terra e ver os "press-releases" e noticias disponíveis no site institucional, percebe-se que a grande visibilidade midiática nacional e internacional tem sido, não só um significativo meio de divulgação das ações ambientais e resultados conseguidos de forma surpreendente, como também, e talvez até mais importante, um conscientizador de cidadania e incentivo para que outros proprietários de terras do bioma tomem a decisão de criar RPPNs.

As atividades da RPPN não se resumem ao plantio de árvores e recuperação de olhos d'água. O Instituto Terra é um polo irradiador de uma nova consciência ambiental tendo para isso criado em 2002 o Centro de Educação e Recuperação Ambiental (CERA).

Sua missão é contribuir para o processo de recuperação do meio ambiente e o desenvolvimento sustentável da Mata Atlântica, em especial na região do Vale do Rio Doce.

bougainvilles e ipês floridos, se multiplicam instalações em madeira de eucaliptos, projetados por Lélia, arquiteta de formação. Elas abrigam um laboratório de sementes coletadas num raio de 300 quilômetros, um centro ecológico educativo com refeitório, 140 leitos, salas de aula, teatro, cinema e até mesmo um pequeno museu. (Tradução nossa). 
Mais de 700 projetos educacionais já foram desenvolvidos para um público estimado em 65 mil pessoas, de mais de 170 municípios do Espirito Santo, Minas Gerais e até mesmo Rio de Janeiro.

This is also a project born of an initiative that my wife, Lélia Deluir. Wanick, and I took to reforest 1,500 acres of land that we own in Brazil with the original species of the Atlantic Forest, one of the 25 hotspots of the planet. From the beginning, the idea was to create a pilot project that could serve as a model for regreening deforested and depleted land across Brazil. To ensure that our experience was shared, we also founded the Instituto Terra to provide a practical environmental education to municipal officials, teachers, farmers and students. We have already planted half a million trees, while our school has graduated its first generations of students. We believe Instituto Terra is demonstrating that it is possible to turn back the clock and recover what seemed lost forever. Sebastião Salgado (THE GUARDIAN, 2004). ${ }^{6}$

A estratégia do CERA é trabalhar um público importante para a recuperação e conservação ambiental local e regional tais como: professores de escolas técnicas agrícolas e florestais, de ensino fundamental e médio e também lideranças politicas como Prefeitos,

\footnotetext{
${ }^{6}$ Este também é um projeto nascido de uma iniciativa de minha esposa, Lélia Deluiz Wanick, e eu para reflorestar 1.500 hectares de terra que possuímos no Brasil com as espécies originais da Mata Atlântica, um dos 25" hotspots "da planeta. Desde o início, a ideia era criar um projeto piloto que poderá servir de modelo para regenerar áreas desmatadas e terra empobrecida em todo o Brasil. Para garantir que a nossa experiência seja compartilhada, nós também fundamos o Instituto Terra para proporcionar uma educação prática ambiental para funcionários municipais, professores, agricultores e estudantes. Nós já plantamos meio milhão de árvores, enquanto a nossa escola já formou suas primeiras gerações de estudantes. Acreditamos que o Instituto Terra está demonstrando que é possível voltar no tempo e recuperar o que parecia perdido para sempre ". Sebastião Salgado (Tradução nossa)
}

Secretários de Meio Ambiente e principalmente produtos rurais da região. (TERRA, 2015)

Em 2004 foi criado o NERE (Núcleo de Estudos em Restauração Ecossistêmica com o objetivo de proporcionar formação póstécnica, teórica e prática. O NERE quer ser referencia na capacitação de profissionais em recuperação de áreas degradadas.

\section{A IFC (International Finance} Corporation) financiou a criação do curriculum do curso e a Philips do Brasil e Fundação Florindon da Suíça colaboraram para a construção da residência dos alunos que ficam hospedados nos alojamentos, recebem alimentação, roupas e ajuda de custo mensal.

Sebastião Salgado, em encontro do SESC-MG e diante de um público bem interessado na temática ambiental continua defendendo a necessidade de recuperar o que perdemos e proteger o que ainda nos resta. Para ele é tudo uma questão de postura quando diz:

\footnotetext{
A água não está acabando porque parou de chover: é porque, em busca do crescimento, matamos os nossos córregos e rios. $O$ desafio agora é mudar a postura, fazendo com que as empresas entendam que, sem água, não há produção. E explicando para as comunidades que, sem água, a aglomeração nos grandes centros urbanos precisará ser redistribuida. A solução está na recuperação ambiental. Juntos, podemos reconstruir. (SESC/MG, 2015).
}

Cerca de $80 \%$ de todas as terras do bioma mata Atlântica estão em mãos de proprietários privados e é do interesse dos brasileiros e do mundo que iniciativas de 
preservação via RPPN tragam de volta $O$ esplendor da mata atlântica em áreas degradadas, a volta da biodiversidade, o renascer dos rios e contribuam para o futuro das próximas gerações.

\begin{abstract}
"Matamos os nossos rios e as nossas florestas, e não há partido ou político que vá resolver isso sozinho, atesta Sebastião Salgado. Todos somos seres politicos e temos responsabilidades sociais. O Brasil é um País incrivel, mas parece que o brasileiro não percebe isso. Ainda somos muito pessimistas em relação à nossa própria gente. Hoje temos um Brasil moderno, mas que foi construido sobre as florestas e os rios. (SALGADO, 2015)
\end{abstract}

\section{Considerações Finais}

Uma maior conscientização ambiental, só será possível se as pessoas compreenderem o valor do meio ambiente para suas existências.

No dia em que cada habitante do planeta e mais particularmente os brasileiros, entenderem como este problema afeta suas vidas e as próximas gerações, de forma direta e irreversível, o meio ambiente não precisará mais de defensores e nem da importante visibilidade midiática de ações como as que tem o Instituto Terra.

A sociedade já terá aprendido que preservar as florestas, nascentes de águas, rios e a biodiversidade é preservar a própria pele, e destruir tudo isso é fragilizar a economia, a cultura, o emprego, a saúde, a educação e a vida. É legar um futuro sombrio às novas gerações.

A informação eficiente, completa, não tendenciosa sobre ações ambientais, como as realizadas pelo Instituto Terra, é fundamental para a formação de uma consciência e cidadania efetivamente mobilizada para a recuperação e manutenção da biodiversidade.

Existem hoje no Brasil mais de 800 RPPNs, muitas delas como única esperança de salvar milhares de espécies da nossa fauna/flora e muitos cursos de água. Mas é preciso que outros proprietários de fazendas pensem o mundo como Salgado e Feliciano, transformando suas terras em reservas particulares do patrimônio natural.

Por outro lado, ações ambientais sérias e comprovadas precisam chegar ao conhecimento das pessoas. Não através daquele tipo de comunicação/propaganda enganosa que muitas empresas fazem para se mostrarem socialmente e ambientalmente responsáveis. A Vale (que antes era do Rio Doce), por exemplo, recebeu em 2012 o prêmio de pior empresa do ano, não obstante rios de dinheiro que ela dispende anualmente com "comunicação". A justificativa do prêmio : "70 anos de história manchada por repetidas violações dos direitos humanos, condições desumanas de trabalho, pilhagem do patrimônio público e pela exploração cruel da natureza". (CIARELLI, 2012) 
Devemos tentar reverter os danos e acreditar que cada semente lançada à terra vai vingar, assim como todo homem é passivel de transformação. Então, a sociedade torna-se reflexo do poder dos seus indivíduos em transformar o meio que já existe. Assim como o sal, devemos encher nossa comunidade de sabor e conservar o que há de extraordinário. (PARAGUASSÚ, 2015)

A viagem ao frágil Vale do Rio Doce atingiu plenamente o objetivo inicial de ver a grande realização do fotografo Sebastião Salgado e de sua esposa Lélia que conseguiram replantar em suas terras uma nova mata atlântica, a primeira do Brasil em área totalmente degradada. Um grande exemplo a ser seguido por mais brasileiros, notadamente grandes proprietários de terras.
Referências bibliográficas

ALMEIDA, Zenolia. Rio Doce-Personagem de
muitas histórias. Disponível em
< http://adesggv.com.br/index.php/rio-doce-
personagem-de-muitas-historias/>Acesso em 25 nov. 2015

ANDRADE, Carlos Drummond de. Lira Itabirana. 1984 - Jornal Cometa Itabirano. Disponível

em:http://zh.clicrbs.com.br/rs/noticias/notici a/2015/11/poema-de-drummond-sobre-o-riodoce-que-circula-em-redes-sociais-nunca-foipublicado-em-livro-4905072.html Acesso: 23 nov.2015

ANDRADE, Carlos Drummond de -Itatiaia. Disponível em

http://www.itatiaia.com.br/blog/jose-linosouza-barros/ser-mineiro-carlos-drummondde-andrade Acesso: 23 NOV.2015

CASTRO, Pedro. Matamos nossos rios, não há partido que resolva. [S1.]: CARTA CAPITAL [online]. 24 mar. 2015. Disponível em: $<$ http://www.cartacapital.com.br/cultura/mata mos-nossos-rios-nao-ha-partido-que-resolvaisso-diz-sebastiao-salgado-6562.html>. Acesso em: 30 set. 2015.

CIARELLI, Monica. Disponível em: http://economia.estadao.com.br/noticias/nego 
cios,vale-recebe-titulo-de-pior-empresa-domundo,100790e. Acesso em 22 nov. 2015

CLARIN. Sebastião Salgado, el fotógrafo que resucitaba los bosques. [on-line]. 27 jul. 2015.

Disponível em: $<$ http://www.clarin.com/cultura/Sebastiao_Sa lgado-ecologia-

reforestacion_0_1401460432.html>. Acesso em: 30 set. 2015.

EL MUNDO. El paraiso replantado de Sebastião Salgado. [on-line]. 2015. Disponível em: <http://www.elmundo.es/cronica/2015/08/1 7/55cf2172e2704e104d8b4571.html>. Acesso em: 30 set. 2015.

FERRARA, L. D. Olhar periférico: informação, linguagem, percepção ambiental. 1. ed. São Paulo: Edusp, 1999.

FRANCASTEL, P. A realidade figurativa. 1. ed. São Paulo: Perspectiva/USP, 1993.

FREITAS, Janio de.Sebastião Salgado: As melhores fotos. Apresentação Janio de Freitas. Disponível em: https://www.escritoriodearte.com/artista/seba stiao-salgado/ Acesso em 20 nov.2015.

GONÇALVES, Domingos Sávio; REIS, Joel Santos. BRASIL: panorama histórico das unidades de conservação. São Roque, SP: IFSP - Instituto
Federal de Educação, Ciência e Tecnologia de São Paulo, Dissertação (TCC), 2014.

GOMES, Patrícia. Da Escrita a Imagem: da fotografia à subjetividade. 1996. Dissertação (Mestrado em Psicologia)- Instituto de Psicologia, Universidade Federal do Rio Grande do Sul, Porto Alegre,1997.

INEA-RJ. Ramos, Marilene 2012- Plano de Manejo de RPPN -Disponível em <http://www.inea.ri.gov.br/cs/groups/public/ documents/document/zwew/mde1/ edisp/in ea0015151.pdf $>$ Acesso: 27 nov.2015

INPE - INPE - Instituto Nacional de Pesquisas Espaciais. SOS Mata Atlântica e INPE apresentam dados do Atlas dos Remanescentes Florestais da Mata Atlântica. [on-line]. 27 mai. 20014 Disponível em:

$<$ http://www.inpe.br/noticias/noticia.php?Co d_Noticia $=3610>$ Acesso em: 29 set. 2015. Atlas Remanescentes Florestais. [online]. Disponível em: $<$ http://mapas.sosma.org.br> Acesso em: 29 set. 2015.

ISÈRE, Karen. Sebastiao Salgado: au commencement était la terre. Environnement. Paris: PARIS MATCH, 22. Avr. 2013. [on-line]. Disponível em: $<$ http://www.parismatch.com/Actu/Environn 
ement/Sebastiao-Salgado-au-commencementetait-la-terre-508750>. Acesso em: 02 out. 2015.

LEITÃO, Miriam. Périplo em busca de águas mais limpas. Rio de Janeiro: O GLOBO [on-line], 19 abr. 2015. Disponível em: $<$ http://oglobo.globo.com/sociedade/sustenta bilidade/instituto-inicia-projeto-para-protegernascentes-do-vale-do-rio-doce-115922872\#ixzz3oQXf1 teQ>. Acesso em: 30 set. 2015.

MILARÉ, Édis. Direito do Ambiente: doutrina, prática, jurisprudência, glossário. $1^{\mathrm{a}}$ ed. rev.atual. ampl. São Paulo: Revista dos Tribunais, 2001.

MONTEIRO, Mário Bitt. 1998. um ensaio sobre o momento da fotografia, suas relações com a comunicação globalizada e sua atual configuração acadêmica na ufrgs. Disponível em: $<\underline{\text { http://www.ufrgs.br/fotografia/port/07 arti }}$ gos/01 atg/ > Acesso em: 21 nov.2015

MURITIBS, Maiara. Sebastião Salgado.Disponivel em: http://www2.eca.usp.br/cms/index.php?optio $\underline{\mathrm{n}=\mathrm{com} \text { content } \& v i e w=\text { article } \& \mathrm{id}=67: \text { sebastia }}$ o-salgado\&catid=14:folios\&Itemid=10.Acesso: 28 nov. 2015.

NERY, Marcello Silva. Conservação Internacional (CI-Brasil) Disponível em: $<$ http://www.conservation.org/global/brasil/
noticias/Pages/entrevista-sobre-a-rppn-

feliciano-miguel-abdala.aspx $>\quad$ Acesso: 22 nov.2015

PARAGUASSÚ, Atila. O outro lado de Sebastião Salgado. [S.l.: s.n.], 2015. [on-line]. Disponível em:

<http://obviousmag.org/claraboia/2015/03/o -outro-lado-de-sebastiao-salgado.html>. Acesso em: 12 out. 2015.

PASCHOAL, Fábio. Curiosidade Animal. Disponível em: $<$ http://viajeaqui.abril.com.br/nationalgeographic/blog/curiosidade-animal/muriquio-maior-primata-das-americas-emascote-dasolimpiadas-de-2016/>.Acesso 22 nov.2015

PLANETA ORGÂNICO. Instituto Terra. [online]. Disponível em: $<$ http://planetaorganico.com.br/site/index.ph p/instituto-terra/>. Acesso em: 04 out. 2015.

SALGADO, S. Em OGLOBO $<$ http://oglobo.globo.com/brasil/o-rio-agorauma-calha-esteril-cheia-de-lama-diz-sebastiaosalgado-18098922> Acesso 22 NOV.2015 
SESC/MG - Central de notícias. Um novo olhar sobre a questão da água: Sebastião Salgado e Lélia Wanick em edição especial do Sempre Um Papo no Sesc Palladium. [on-line]. 10 mar. 2015. Disponível em: $<$ http://www.sescmg.com.br/wps/portal/sesc $\mathrm{mg} /$ centrais/central_noticias/noticia_aberta/c ulturat-

+ noticias/sempre + um + papo + sebastiao + salga do>. Acesso em: 04 out. 2015.

SILVA, H. P. A (im)provável pegada ambiental: Uma provocação antropológica sobre o ideal de sustentabilidade entre os "povos indígenas". Amazônica Revista de Antropologia, UFPA, v. 5, n. 3, p. 882-891, 2013. Disponível em: $<$ http://www.periodicos.ufpa.br/index.php/a mazonica/article/viewFile/1609/2029>. Acesso em: 30 set. 2015.

SILVA, J. Afonso da. Direito Ambiental Constitucional. $3^{\mathrm{a}}$ ed. rev.atual. São Paulo: Malheiros, 2000.

TERRA, Instituto. Site Institucional. Disponível em http://www.institutoterra.org/pt br/conteudo sLinks.php?id $=24 \& \mathrm{tl}=\mathrm{SW} 5 \mathrm{mb} 3 \mathrm{JtYef1ZXM}=\&$

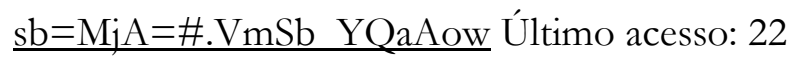
nov.2015

THE GUARDIAN. Be fruitful, and replenish the earth . [on-line]. Disponível em:
$<$ http://www.theguardian.com/artanddesign/2 004/sep/11/sebastiaosalgado.photography1>. Acesso em: 04 out. 2015.

VALE, Fundação. Aimorés. Documento de Visão Estratégica, 2006/2026.Disponível em : http://www.bari.org.br/uploads/publicacao/D oc.V.Estrategica Aimores.pdf $>$ Último acesso:21 nov.2015

VERAS, Lucia. Por que a paisagem é importante?Por que conservar a paisagem histórica do centro do Recife? 2013- Disponível em: $<$ http://www.clubedeengenhariadepe.com.br/ 20130129luciaveras.pdf >Acesso em 23 nov.2015

WWF-Brasil. Mata Atlantic. [on-line]. Disponível em: $<$ http://www.wwf.org.br/natureza_brasileira/ questoes_ambientais/biomas/bioma_mata_atl/ >. Acesso em: 28 set. 2015

URBAN, T. Um novo olhar da mídia sobre o meio ambiente. [S.l.: s.n.], 2006. [on-line] Disponível em:

<http://www.comscientianimad.ufpr.br/2006/ 01/ponto-de-vista/tereza_urban_u m_novo_olhar.pdf $>$. Acesso em: 12 out. 2015.

ZARACHOWICZ, Weronika. Chez les Salgado, au Brésil: objectif forêt. Paris: TÉLÉRAMA Sortir Paris, 2014. [on-line]. Disponível em: $<$ http://www.telerama.fr/monde/chez-les- 
salgado-au-bresil-objectif-foret,117763.php>.

Acesso em: 01 out. 2015. 